\title{
Analisis Layanan Branchless Banking Terhadap Number Of Account (Noa) Dan Customer Satisfaction (Studi tentang Layanan BNI Agen46 Kantor Cabang Kediri) \\ Venoncia Irene Kurnia Dewi, Debby Satyo Rusandy \\ Mahasiswa Magister Manajemen Pascasarjana Universitas Islam Kadiri
}

\begin{abstract}
Abstrak
Penelitian ini bertujuan untuk mengetahui apakah kualitas layanan yang diberikan oleh Agen46 BNI KC Kediri berpengaruh terhadap penambahan NOA (Number of Account) dan kepuasan pelanggan.

Penelitian ini dilakukan di BNI KC Kediri. Populasi dalam penelitian ini adalah seluruh nasabah BNI yang menggunakan jasa dari Agen46 baik untuk pembukaan rekening, transfer dana, penarikan, setoran, pembayaran, dan pembelian. Dari data yang telah dikumpulkan peneliti, ditemukan bahwa jumlah nasabah BNI Kediri yang menggunakan jasa Agen46 sebanyak 1571. Sedangkan jumlah sampel yang digunakan oleh peneliti adalah 94 nasabah Agen46 BNI KC Kediri. Jumlah ini didapat dari cara pengambilan sampel yang dikembangkan oleh Isaac dan Michael.

Metode pengumpulan data primer pada penelitian ini dilakukan dengan menggunakan metode survei, yang bertujuan untuk mengumpulkan informasi dari responden dengan menggunakan kuesioner berisi daftar pernyataan yang disampaikan langsung kepada responden. Berdasarkan penelitian yang dilakukan, diperoleh adanya pengaruh antara kualitas layanan $(\mathrm{X})$ dengan $\mathrm{NOA}(\mathrm{Y} 1)$ dan kepuasan pelanggan (Y2).
\end{abstract}

kata kunci : Kualitas layanan, NOA, kepuasan pelanggan, branchless banking,Agen46.

\begin{abstract}
This study aims to determine whether the quality of service provided by Agen 46 BNI KC Kediri has an effect on the addition of NOA (Account Number) and customer satisfaction or not.

This research was conducted at BNI KC Kediri. The population in this study is all of BNI customers who use the services of Agen46 for account opening, fund transfers, withdrawals, deposits, payments, and purchases. From the data collected by the researchers, it was found that the number of BNI Kediri customers who used the services of Agen46 was 1571. The researcher used 94 customer of Agen 46 BNI KC Kediri as her sample. This number is obtained from the sampling method developed by Isaac and Michael.

The primary data collection method in this study was conducted using a survey method, which aims to collect information from respondents by using a list of statements that were submitted directly to respondents. Based on the research conducted, it is found that there is an influence between service quality $(X)$ with NOA (Y1) and customer satisfaction (Y2).
\end{abstract}

Keywords: Service quality, NOA, customer satisfaction, branchless banking, Agen46.

\section{Latar Belakang Teoritis}

Meningkatnya persaingan dalam bidang bisnis penyedia jasa seperti perbankan menciptakan tantangan tersendiri bagi para penyedia jasa untuk memahami kebutuhan dan keinginan para konsumen dengan cara memberikan layanan yang lebih baik daripada pesaingnya. Menurut Direktur Industri Perbankan dan Jasa Finansial PT Nielsen Indonesia, Dena Firmayuansyah, yang dicatut oleh situs berita wnw sindonews.com, rendahnya rentang tahun nasabah di suatu bank, yang diacu oleh survei Nielsen terhadap 1.900 orang dan menjelaskan bahwa rata-rata nasabah di Indonesia berpindah bank hanya dalam waktu 3,7 tahun, menunjukkan nasabah sering berpindah perbankan dengan alasan ketersediaan anjungan tunai mandiri/ATM (62\%), kantor cabang (61\%), dan lokasi strategis $(56 \%)$. Sadar akan pentingnya jangkauan lokasi, banyak perbankan yang mulai melebarkan sayapnya seperti berlomba lomba untuk membangun kantor cabang pembantu dan juga memperbanyak mesin ATM.

Meskipun para direksi Bank-Bank ternama tersebut mengetahui bahwa jumlah ATM dan kantor cabang sangat mempengaruhi jumlah NOA (Number of 
Account) yang ada, tetapi mereka tidak serta merta melakukan pembangunan dan pembukaan kantor cabang pembantu ataupun kantor kas di wilayah kelolaannya dengan gegabah. Hal ini disebabkan oleh adanya bianya operasional yang harus dikeluarkan oleh bank. Biaya operasional tersebut mencakup biaya SDM seperti gaji para pegawai, nominal yang harus dikeluarkan untuk menyewa bangunan setiap tahunnya, listrik, air, kertas, dan beberapa hal kecil lainnya seperti pembayaran sampah pun juga harus dikeluarkan oleh pihak perbankan. Biaya operasional ini tentunya menggerus keuntungan perusahaan. Oleh sebab itulah, direksi berusaha mencari cara agar dapat membuka kantor cabang tanpa harus mengeluarkan biaya operasional yang tinggi. Dari situ munculah ide untuk merekrut agen untuk dapat membantu transaksi perbankan seperti pembukaan rekening, transfer, penarikan tunai, pembayaran-pembayaran listrik, PDAM, dan bahkan pembelian pulsa. Agen yang direkrut biasanya merupakan pemilik warung dan bukan dari kalangan pegawai bank tersebut. Agen tersebut dibukakan rekening khusus untuk transaksi keagenan, dibekali dengan mesin EDC (Electronic Data Capture) dan juga aplikasi yang sangat mirip seperti yang digunakan oleh teller dan customer service. Agen tersebut akan diberikan fee oleh Bank pengguna jasanya sesuai dengan banyaknya transaksi yang dilakukan di tempat keagenannya. Pada akhirnya BNI mengeluarkan produk keagenan yang bernama AGEN46.

Selain itu, perbankan juga harus memperhatikan kualitas layanan yang diberikan oleh para Agen46. Hal ini dikarenakan oleh jika menerima kualitas layanan yang lebih rendah daripada ekspektasinya, maka mereka tidak akan kembali menggunakan jasa tersebut, begitupun sebaliknya. Oleh sebab itulah peneliti sangan tertarik untuk mempelajari apakah kualitas layanan yang diberikan oleh Agen46 BNI KC Kediri sudah cukup bagus dan berpengaruh terhadap NOA dan kepuasan pelanggan atau tidak.

\section{Kajian Teori}

\section{Kualitas Layanan}

Menurut Tjiptono (2006:65), kualitas merupakan suatu kondisi dinamis yang berpengaruh dengan produk, jasa, manusia, proses, dan lingkungan yang memenuhi atau melebihi harapan. Hal ini juga didukung dengan adanya pendapat dari Kotler (1997) bahwa kualitas layanan merupakan suatu bentuk penilaian konsumen terhadap tingkat layanan yang diterima (perceived services) dengan tingkat layanan yang diharapkan (expected services).

Sehingga kualitas layanan dapat diartikan sebagai suatu usaha untuk pemenuhan keinginan dan kebutuhan nasabah agar dapat memberikan produk dan jasa yang sesuai dan bahkan dapat melebihi ekspektasi nasabah.

\section{Branchless Banking}

Carmel \& Scott (2009) mendefinisikan branchless banking sebagai bentuk penyaluran atau pelayanan jasa keuangan kepada masyarakat di luar cabang bank yang tradisional dengan menggunakan teknologi informasi (ICT). Dalam bahasa Indonesia, Branchless Banking disebut juga dengan Laku Pandai, kependekan dari Layanan Keuangan Tanpa Kantor dalam Rangka Keuangan Inklusif.

\section{BNI Agen 46}

BNI Agen46 merupakan produk Branchless Banking yang dikeluarkan oleh PT. Bank Negara Indonesia (Persero), Tbk. Agen46 merupakan perpanjangan tangan dari BNI untuk dapat menjangkau nasabahnasabah yang bertempat tinggal jauh dari kantor cabang. Agen46 ini dapat melayani berbagai macam transaksi perbankan seperti yang ada di Kantor Cabang.

\section{Number Of Account (NOA)}

Number of Account (NOA) dalam istilah perbankan berarti jumlah rekening yang ada di suatu Bank. NOA tidak mengacu kepada berapa banyaknya nasabah. NOA hanya mengacu kepada berapa banyaknya rekening yang ada di suatu Bank. Jadi satu nasabah bisa memiliki beberapa NOA, misalnya saja ada satu nasabah memiliki beberapa rekening tabungan seperti satu tabungan biasa, satu tabungan berjangka, dan satu tabungan deposito, ini berarti nasabah tersebut memiliki tiga NOA.

\section{Kepuasan Pelanggan}

Menurut Tjiptono dalam Noviyantie (2001), kepuasan pelanggan merupakan evaluasi pembeli dimana alternative yang 
dipilih sekurang-kurangnya memberikan hasil (outcome) sama dengan harapan pelanggan. Pendapat ahli yang lain, yakni Sunarto (2003:25), kepuasan konsumen adalah Perasaan senang atau kecewa seseorang yang muncul setelah membandingkan antara presepsi/kesannya terhadap kinerja suatu produk dan harapan-harapannya. Selain itu, menurut Kottler (2000:35) kepuasan pelanggan adalah tingkat perasaan seseorang setelah membandingkan kinerja atau hasil yang dia terima dibandingkan dengan harapannya.

Sehingga dapat kita artikan bahwa kepuasan pelanggan dapat mempengaruhi tingkat kemajuan suatu perusahaan penyedia jasa. Pelanggan yang merasakan puas pada pelayanan penyedia jasa akan terus menerus menggunakan jasa tersebut dan bahkan bisa jadi mempromosikannya kepada orang lain. Sebaliknya, pelanggan yang tidak puas dan bahkan mersakan kekecewaan, akan berhenti menggunakan jasa tersebut.

\section{Metode Penelitian}

Peneliti menggunakan metode kuantitatif. Menurut Sugiyono (2015, 7) metode kuantitatif merupakan metode tradisional, karena metode ini sudah cukup lama digunakan sehingga sudah mentradisi sebagai metode untuk penelitian. Analisa Kuantitatif yang digunakan adalah $\mathrm{Uji}$ Validitas dan Uji Reliabilitas.

Penelitian ini akan dilakukan di seluruh Kantor Cabang BNI Kediri. BNI Kediri juga memperoleh penghargaan dikarenakan akuisisi Agen46 tertinggi tahun 2019, sehingga mendukung tujuan dari penelitian ini yang berhubungan dengan kepuasan nasabah dengan layanan keagenan BNI Agen46.

Dari data yang telah dikumpulkan peneliti, ditemukan bahwa jumlah nasabah BNI Kediri yang menggunakan jasa Agen46 sebanyak 1571. Pengambilan sampel pada penelitian ini dilakukan dengan cara penentuan jumlah sampel dari populasi tertentu yang dikembangkan oleh Isaac dan Michael. Menurut Sugiyono (2015, 86), jumlah sampel tergantung pada tingkat ketelitian atau kesalahan yang dikehendaki. Untuk penelitian ini, peneliti menggunakan tingkat kesalahan 10\%. Menurut Sugiyono $(2015,87)$, untuk populasi yang jumlahnya tidak terbatas, dengan tingkat kesalahan 10\%, jumlah sampel untuk penelitian berjumlah 94 jiwa. Jumlah tersebut diperoleh dari hasil perhitungan sebagai berikut:

$$
\begin{array}{r}
s=\frac{1571}{\left(1571 \times 10 \%^{2}\right)+1} \\
s=\frac{1571}{16,71} \\
\mathrm{~s}=94,01 \approx 94
\end{array}
$$

Metode pengumpulan data primer pada penelitian ini dilakukan dengan menggunakan metode survei, yang bertujuan untuk mengumpulkan informasi dari responden dengan menggunakan kuesioner berisi daftar pernyataan yang disampaikan langsung kepada responden, yaitu nasabah BNI Agen46. Alasan penggunaan metode ini adalah responden dapat memperhatikan dan mempertimbangkan pernyataan dan jawaban dengan jelas, pewawancara dapat menggali informasi yang lebih rinci dan juga dapat mengontrol pertanyaan yang diberikan.

Dalam penelitian ini, peneliti menggunakan dua variabel yang terdiri dari variabel bebas dan variabel terikat. Peneliti akan menguji adanya hubungan dan pengaruh antara kedua variabek tersebut. Untuk memudahkan pelaksanaan penelitian ini dan tidak menimbulkan persepsi yang lain, variabel yang digunakan terdiri dari variabel bebas (x) dan variabel terikat (y). secara rinci, definisi opeasional untuk masing-masing variabel sebagai berikut:

a. Variabel Bebas (X)

Variabel Bebas dari penelitian ini adalah Layanan Branchless Banking

1) Tangible (X1)

a) Letak Agen46 yang strategis (X1.1)

b) Fasilitas Agen46 canggih (X1.2)

c) Pelayanan BNI Agen46 hampir setara dengan Kantor Cabang (X1.3)

2) Reliability (X2)

a) Kemampuan BNI Agen46 memberikan pelayanan yang sesuai dengan standar layanan (X2.1)

b) Kemampuan BNI Agen46 dalam merespon komplain nasabah kelolaannya (X2.2)

c) Ketepatan BNI Agen46 dalam memberikan informasi (X.2.3)

3) Responsiveness (X.3)

a) Kecepatan pelayanan yang diberikan kepada nasabah BNI Agen46 (X3.1) 
b) Kemudahan pengaduan keluhan kepada BNI Agen46 (X3.2)

c) Kecepatan dan kesigapan dalam menangani keluhan (X3.3)

4) Assurance (X4)

a) Proses pelayanan cepat (X4.1)

b) Kejujuran BNI Agen46 (X4.2)

c) Kemampuan BNI Agen46 dalam menguasai informasi produk dan layanan BNI (X4.3)

5) Empathy (X5)

Agen46 bersedia mendengarkan dan memahami keluhan nasabah (X5.1)

b. Variabel Terikat (Y)

1. Number of Account (Y1)

a) Pembukaan rekening di Agen46 (Y1.1)

b) Peningkatan NOA di BNI Kediri (Y1.2)

2. Customer Satisfaction (Y2)

a) Nasabah mendapatkan produk jasa layanan yang sesuai dengan harapannya (Y2.1)

b) Nasabah mendapatkan jasa pelayanan sesuai dengan harapan (Y2.2)

c) Kualitas pelayanan sudah sesuai dengan harapan nasabah (Y2.3)

d) Penyelesaian masalah sudah sesuai dengan harapan nasabah (Y2.4)

\section{Metode Pengumpulan Data}

1. Observasi, yaitu Peneliti mengmpulkan data melalui pengamatan langsung di tempat penelitian. Peneliti mengamati kegiatan pelayanan yang diberikan oleh Agen46 di wilayang Kantor Cabang Kediri.

2. Kuesioner, digunakan untuk menghimpun data secara langsung dari nasabah BNI (responden) yang menggunakan jasa Agen46 dengan pertanyaan-pertanyaan yang tertutup (pilihan jawaban sudah disediakan pada angket, para responden diberi tugas untuk memilih jawaban sesuai dengan yang dirasakan)

3. Dokumentasi, yaitu pengambilan sebuah data melalui dokumendokumen, foto-foto, ataupun arsiparsip yang diperlukan.

\section{Pembahasan}

1. Uji Validitas

Berdasarkan tabel Hasil Pengujian Validitas dapat diketahui bahwa semua nilai korelasi diatas 0,3 dan nilai probbabilitas dibawah 0,5, sehingga dapat disimpulkan bahwa semua item pertanyaan dalam uji kuesioner adalah Valid.

2. Uji Reliabilitas

Berdasarkan tabel Hasil Pengujian Reliabilias, nilai Alpha Cronbach Untuk Kualitas Layanan (X1) adalah 0,791, NOA (Y1) adalah 0,718, dan untuk Customer Satisfaction (Y2) adalah 0,985

Untuk menjawab rumusan masalah dan hipotesis pada penelitian ini dilakukan analisis regresi 2 kali, yaitu yang pertama antara variabel layanan nasabah (X) dengan number of account (Y1) dan yang kedua antara variabel layanan nasabah $(\mathrm{X})$ dengan customer satisfaction (Y2).

1. Regresi Linier Variabel Layanan Nasabah

(X) dengan NOA (Y1).

Berdasarkan tabel Hasil Uji Regresi

Linier Variabel Layanan Nasabah dengan

NOA, dapat disusun persamaan regresi

sebagai berikut :

$$
\mathrm{Y}=1,868+0,587 \mathrm{X}
$$

Dari persamaan tersebut dapat dijelaskan :

a. Konstanta $=1,868$

Besarnya konstanta 1,868 menunjukkan bahwa apabila tidak ada pengaruh layanan nasabah maka nilai number of account adalah sebesar 1,868.

b. Koefisien regresi variabel layanan nasabah $=0,587$

Besarnya koefisien regresi variabel layanan nasabah sebesar 0,587 menunjukkan bahwa apabila layanan nasabah meningkat 1 satuan maka number of account akan meningkat sebesar 0,587 satuan.

Tabel Hasil Uji Regresi Linier Variabel Layanan Nasabah dengan NOA juga menunjukkan nilai $\mathrm{t}$ hitung sebesar 4,733 dengan probabilitas (sig.) 0,000. Oleh karena nilai probabilitas (sig.) lebih kecil dari 0,05 $(0,000<0,05)$, maka hal ini membuktikan bahwa variabel layanan nasabah berpengaruh signifikan terhadap number of account. Dengan demikian hipotesis 1 yang menyatakan "layanan nasabah mempengaruhi perolehan NOA BNI Kantor Cabang Kediri" adalah terbukti.

2. Regresi Linier Variabel $\begin{gathered}\text { Layanan } \\ \text { Nasabah }(\mathrm{X}) \text { dengan }\end{gathered}$
$\begin{aligned} & \text { Cutisfaction }(\mathrm{Y} 2) \\ & \text { Berdasarkan tabel Hasil Uji Regresi }\end{aligned}$
Linier Variabel Layanan Nasabah dengan


Customer Satisfaction, dapat disusun persamaan regresi sebagai berikut :

$$
\mathrm{Y}=1,160+0,770 \mathrm{X}
$$

Dari persamaan tersebut dapat dijelaskan :

a. Konstanta $=1,160$

$$
\text { Besarnya konstanta 1,160 }
$$

menunjukkan bahwa apabila tidak ada pengaruh layanan nasabah maka nilai customer satisfaction adalah sebesar 1,160.

b.Koefisien regresi variabel layanan nasabah $=0,770$

Besarnya koefisien regresi variabel layanan nasabah sebesar 0,770 menunjukkan bahwa apabila layanan nasabah meningkat 1 satuan maka customer satisfaction akan meningkat sebesar 0,770 satuan.

Tabel Hasil Uji Regresi Linier Variabel Layanan Nasabah dengan Customer Satisfaction juga menunjukkan nilai t hitung sebesar 16,379 dengan probabilitas (sig.) 0,000 . Oleh karena nilai probabilitas (sig.) lebih kecil dari 0,05 (0,000<0,05), maka hal ini membuktikan bahwa variabel layanan nasabah berpengaruh signifikan terhadap customer satisfaction. Dengan demikian hipotesis 2 yang menyatakan "Layanan BNI Agen46 berpengaruh pada kepuasan nasabah di BNI Kantor Cabang Kediri” adalah terbukti.

\section{Daftar Pustaka}

Anton, Bawono. (2006). Multivariate Analysis dengan SPSS. Salatiga: STAIN.

Arikunto. (2010). Prosedur penelitian (suatu pendekatan praktik). Jakarta: Rineka Cipta.

Carmel, H. \& Scott. W. (2009). E-retailing by Banks: E-Service Quality and Its Importance to Customer Satisfaction. European Journal of Marketing, Vol. 43, No. 9/10, pp: 1220-1231

Hasibuan, Malayu S. P. (2008). Manajemen Sumber Daya Manusia. Jakarta: PT. Bumi Aksara

Roy Franedya. 2019. BCA Jawara ATM Tarik Setor, BRI Pemilik ATM terbanyak di

RI. https://www.cnbcindonesia.com/t ech/20191120063248-37-

116463/bca-jawara-atm-tarik-setorbri-pemilik-atm-terbanyak-di-ri

Ardhy Dinata Sitepu. 2014. Rata - rata Nasabah di Indonesia 3,7 tahun Pindah

Bank. https://ekbis.sindonews.com/berit a/941142/34/rata-rata-nasabah-diindonesia-37-tahun-pindah-bank

https://www.ojk.go.id/id/Pages/LakuPandai.aspx

Novia Widya Utami. 2020. 4 Indikator Kepuasan Pelanggan Untuk Bisnis Anda.

https://www.jurnal.id/id/blog/ind ikator-kepuasan-pelanggan-untukbisnis/\#: :text=Menurut $\% 20$ Kotl er $\% 2 \mathrm{C} \% 20$ et $\% 20$ al. $\% 2$, pelanggan $\% 2 \mathrm{C} \% 20$ dan $\% 20$ survey $\% 20$ kepuas an $\% 20$ pelanggan.

Gusti Yuliana. 2014. Pelaksanaan Pasti Pas! SPBU Pada Kualitas Pelayanan Jasa Terhadap Pelanggan Menurut Perspektif Ekonomi Islam (Studi Kasus pada SPBU ABABIL Sukajadi Pekanbaru). http://repository.uinsuska.ac.id/6396/4/

Kotler, Philip. (1997). Marketing Management: Analysis, Planning, Implementation, and Control, 9th Ed. Englewood Cliffs. NJ: Prentice Hall. Inc.

Kotller, P. (2000). Manajemen Pemasaran di Indonesia: Analisis, Perencanaan, Implemenytasi dan Pengendalian. Jakarta: Salemba Empat.

Kriyantono, Rachmat. (2010). Teknik praktis riset komunikasi. Jakarta: Kencana.

Lovelock, Ch., Jochen, W., \& Jacky, M. (2010). Pemasaran jasa, manusia, teknologi, strategi. Jakarta: Erlangga.

Parasuraman, A. (1997). Reflections on Gaining Competitive Advantage Through Customer Value, Journal of The Academy of Marketing Science.

Simamora. (2004). Riset Pemasaran. Jakarta: Gramedia Utama

Sugiyono. (2006). Metode Penelitian Kuantitatif, Kualitatif dan $\mathrm{R}$ \& $\mathrm{D}$. Bandung: Alfabeta.

Sunarto.(2003). Manajemen Pemasaran. BPFE. Yogyakarta.

Tjiptono. F.(1997). Total Service Quality. Yogyakarta: Andi Offset.

Martin, William B. (2005). Quality Customer Service. Jakarta : PPM. 